\title{
Relationship between Gross Motor Skills and Body Mass Index of Children with Intellectual Disability
}

\author{
Kuston Sulton*, Jajat Jajat \\ Faculty of Sport and Health Education, \\ Universitas Pendidikan Indonesia \\ Bandung, Indonesia \\ *Kuston.sultoni@upi.edu
}

\begin{abstract}
Previous studies of typically developing children have reported significant negative relationships between gross motor skills (GMS) and body mass index (BMI). The purpose of this study was to determine if this relationship exists among children with mild intellectual disability (ID). Thirty (30) children(10.2 $\pm 3.1 y r s)$ with mild ID were chosen through stratified random sampling from schools for children with special needs in a metropolitan area. The Test Gross Motor Development-2 (TGMD-2) was used to evaluate GMS. Body mass Index (BMI, $\mathrm{kg} / \mathrm{m} 2)$ was determined and participants were classified as normal weight $(\mathrm{NW})$, overweight $(\mathrm{OW})$, and obese (OB) according to The Quetelet Formula. Relationships between GMS and BMI classifications were determined by a Pearson correlation coefficient. Significant $(\mathbf{p}<0.05)$ negative correlations for locomotor GMS $(\mathbf{r}=\mathbf{- 0 . 3 6 6})$ and object control GMS $(\mathbf{r}=$ 0.506) were observed. The results suggest that the negative relationship between GMS and BMI also exists for children with ID.
\end{abstract}

Keywords-BMI; children with intellectual disability; gross motor skills

\section{INTRODUCTION}

Gross motor skill (GMS) is defined as a skill that covers all parts of the body in the form of moving or stretching [1]. Some of the skills belonging to fundamental ones are namely locomotors, which include run, gallop, jump, slide, skip, and object control such as throw, catch, strike, and kick. The development of gross motor skills; however, plays an important role in children so that they can move forward to mastering the more complicated skills needed in their life [2]. In the meantime, according to Haapala, the development of gross motor skills is not only important for the next level of motor skills, but also for cognitive development such as the efficiency of control and memory [3].

In relation to GMS, not only are those skills important for children in general, but they are also important for children with intellectual disability (to be later referred as ID), considering that children with ID tend to have less physical activity [4]. There are several studies focusing on motor skills in children with intellectual disability [5-7]. Rintala and Loovis, for instance, they compare the motor skills of children with intellectual disability and those of children without ID using test of the gross motor development second edition
(TGMD-2) [5]. The results of their study prove that children with ID perform significantly lower in GMS than children without ID. In the meantime, Simons et al. and Valentini both study the validity and reliability of TGMD-2 for children with ID and they find out that TGMD-2 is valid and reliable to measure GMS to children with ID [6,7].

In addition to GMS's importance to the better quality of life, GMS is also considered one of the core influences of obesity. Gross motor skills have something to do with body mass index (to be later referred as BMI) and vice versa [8,9]. The results of their study highlight that most of the normal children they investigate whose GMS is low tend to have high BMI. It can be interpreted that if the children do not have sufficient GMS, chances are they get fatter more easily [10]. However, there are limited numbers of this kind of study focusing on children with ID. Thus, this study is an attempt to fill in the gap.

As a matter of fact, obesity has become a serious issue in today's era since it affects health on a global scale [11]. In some countries, either developed or developing ones, reducing obesity has become a public effort since it is closely related to health issues. In England, for instance, the obese children, whether with or without intellectual disability (ID) are categorized into a 'high risk' group [12]. Surprisingly, in Indonesia, the obesity prevalence in 2030 is increasing to $5.9 \%$ out of the world population [13]

In an attempt of finding out the correlation between GMS and BMI of children with intellectual disability, Frey and Chow conduct a study whose results conclude that children with ID are considered more overweight, less physically fit, and less motor proficient than children without ID [14]. However, the age range of their respondents seems to be too huge (6-18 years old). In regards to this fact, it is necessary to conduct a study focusing on smaller age range.

Considering the aforementioned reasons, the importance of determining the influential factors in children's obesity and gross motor skills, especially in children with ID, is undeniable. Thus, this study aims to investigate the relationship between gross motor skills and body mass index (BMI) of children with intellectual disability. 


\section{METHOD}

\section{A. Participant}

In total, the participants of the study are 30 children with mild ID ( 7 male and 23 female) coming from five special schools in Bandung ranging from 8 to 12 years old. In Indonesia, the classification of intellectual disability refers to Wechsler (1974) which consists of mild (IQ between 68-52), medium, (IQ between 51-36), and strong (IQ lower than 35) [15]. This study focuses on the mild ID and to categorize the children, the study does not do an IQ test since the schools already classify the children based on their IQ. The group of children with mild ID is selected due to their capability of following the TGMD-2. To select the participants, this study employs stratified random sampling that finally comes up with 5 out of 22 special schools (category C) in 5 different areas. What is meant by category $\mathrm{C}$ here is a special school for children with ID.

\section{B. Instrument}

1) Test Gross Motor Development-Second edition (TGMD-2): The instrument used to measure children's gross motor skills in this study is Test Gross Motor DevelopmentSecond Education (TGMD - 2nd Edition) [16]. TGMD-2 is a very common tool utilized to test the gross motor skills for children without intellectual disability as well so that the validity and reliability tests for the instrument have been conducted in several Countries [7,17-20]. The tests were also proven to be valid and reliable for children with ID [6,21]. Moreover, TGMD-2 has also been used as an instrument in several research studies involving children with ID $[5,14]$. In TGMD-2, there are 12 movements in total which are categorized into two including sub-test Locomotors (run, gallop, hop, leap, horizontal jump, and slide), and object control (striking stationary ball, stationary dribble, catch, kick, overhand throw, and underhand roll). To implement the test, children are asked to perform each skill twice with some preceding examples by the tester(s). Each skill is observed in accordance with the performance record. All the processes of the test are also videotaped so that verification will be easy to take place. To supervise the test, two experts are involved. One person comes from a university whose expertise is in motor development and the other one is a special education teacher who has experiences in dealing with children with ID.

2) Body mass index: To test the BMI, this study administers The Quetelet Formula (World Health Organization Expert Committee 1995) in which weight is divided by height in the square $(\mathrm{kg} / \mathrm{m} 2)$. The interpretation of BMI actually depends on age and gender since men and women have a different fat level. BMI classifications for age 10,5 of normal (Male: <20,2; Female: <20,3), overweight (Male: <24,6; Female: <24,8), and obese (Male: >24,6; Female: $>24,8$ ) are determined using international standards [22].

\section{Data Analysis}

Pearson correlations are calculated to examine relationships between variables and interpreted as (small/weak $0.10-0.29$; medium/moderate 0.30-0.49; large/strong 0.50-1.00) [23].

\section{RESULTS AND DISCUSSIONS}

30 children with a mild intellectual disability performing as the sample of the study followed a series of research procedure such as height and weight measurement and TGMD-2 test. Table 1 shows the descriptive data of mean and standard deviation of such variables as age, height, weight, body mass index, gross motor Skills, locomotor skills and also object control skills.

Based on table 1, it is shown that the mean of BMI is 21.96 which includes overweight category. According to the standard cut of point of BMI for 10.5-year-old children formulated by [22], this means is actually close to obesity. Similar results were also performed by the previous study by Pan [24] with the mean of BMI 21.7. Nevertheless, studies by Frey and Chow showed that the mean was 25.77 which was obviously categorized as obesity [14]. On table 1 , it is also displayed the category of BMI which comprises normal, overweight, and obese. In this study, children categorized into normal are 10 with a mean score of $\mathrm{BMI}=19.94$ and $\mathrm{SD}=0.45$; children categorized into overweight are 12 with the mean score of BMI $=21.38$ and $\mathrm{SD}=0.99$, and children categorized into obese are 8 with a mean score of $\mathrm{BMI}=25.37$ and $\mathrm{SD}=2.30$.

TABLE I. DESCRIPTIVE ChARACTERISTIC

\begin{tabular}{|l|c|}
\hline & Mean \pm Standard Deviation $(\mathbf{n}=30)$ \\
\hline Age & $10.23 \pm 3.06$ \\
\hline Height $(\mathrm{cm})$ & $120.2 \pm 14.89$ \\
\hline Weight $(\mathrm{kg})$ & $31.7 \pm 6.5$ \\
\hline BMI $\left(\mathrm{kg} / \mathrm{m}^{2}\right)$ & $21.96 \pm 2.54$ \\
\hline Normal $(\mathrm{n}=10)$ & $19.94 \pm 0.45$ \\
\hline Overweight $(\mathrm{n}=12)$ & $21.38 \pm 0.99$ \\
\hline Obese $(\mathrm{n}=8)$ & $25.37 \pm 2.30$ \\
\hline Locomotor & $17.77 \pm 3.73$ \\
\hline Object Control & $16.43 \pm 2.48$ \\
\hline GMS & $53.60 \pm 8.60$ \\
\hline
\end{tabular}

Table 1 also shows the results of TGMD-2. The GMS mean score of the sample in this study is $\mathbf{5 3 . 6 0}$ which is lower than that of a previous study by Rintala and Loovis whose mean score is 55.0 [5]. Whereas, the mean score of locomotor skills in this study is 17.77 which is higher than the mean score of object control skills (16.43). This can be interpreted that children with ID have more difficulties in object control skills mastery than in locomotor skills one. As a matter of fact, object control skills are necessary for them to participate in sport [25].

The condition of GMC on locomotors and object control skills can be specifically seen in figure 1 and figure 2 . Figure 1 depicts all six sub-items of locomotors including run, gallop, hop, leap, horizontal jump, and slide. Taking a look at figure 1, this study finds out that the skill performed the best by children with ID is run (2.13) while the other skills such as gallop (1.43), hop (1.37), leap (1.5), horizontal jump (1.63), and slide (1.63) tend to be lower in a quite huge gap. This might be 
caused by the complexity of each item. Run is considered easier since children do not have to do any pre-set activities; they can do it naturally while the other skills need to be designed carefully so that the children need more focus and efforts to do it [26].

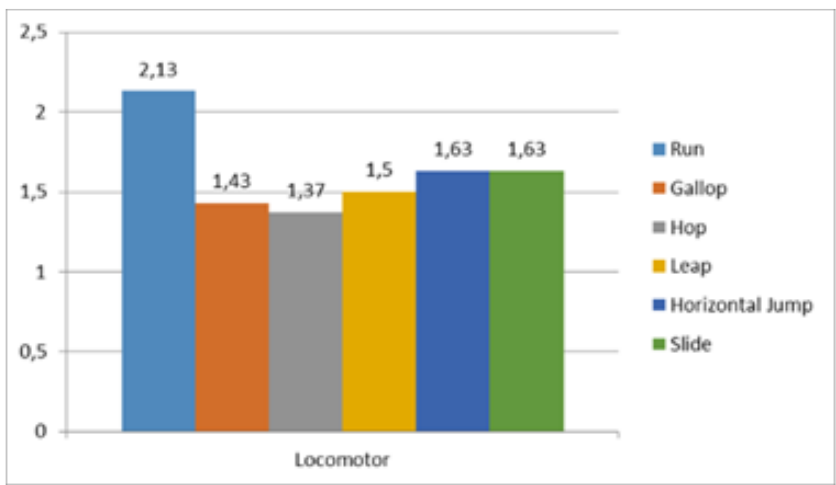

Fig. 1. Mean of locomotor skills.



Fig. 2. Mean of object control skills.

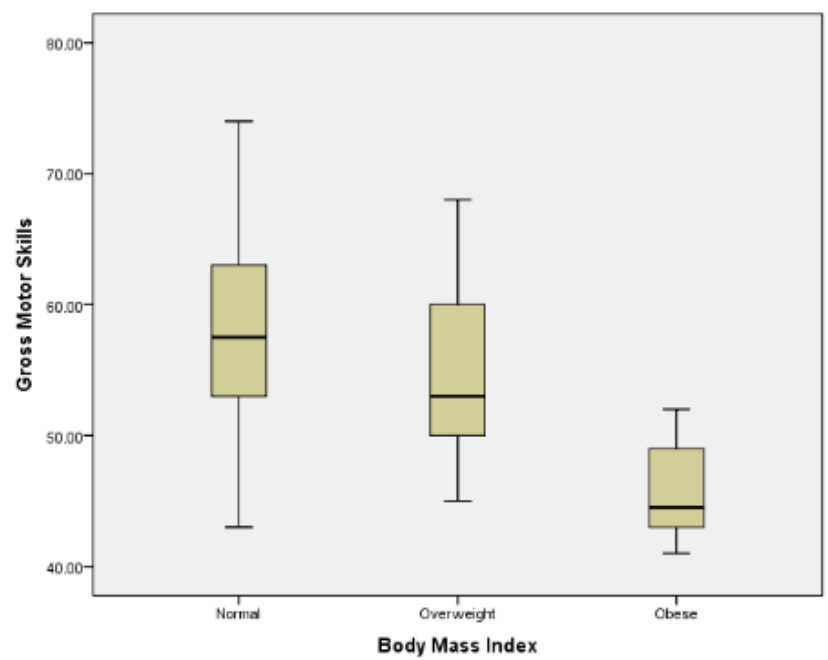

Fig. 3. Mean of GMS based on BMI category.

The condition of sub-test on object control skills, on the other hand, is displayed in figure 2. In this figure, the superior skill is an underhand roll (2.23) while the other skills such as strike (1.67), dribble (1.10), catch (1.83), kick (1.50), and overhead throw (1) seem to be low. This makes sense since teachers in Special Education schools tell that there is a sports competition specially designed for children with ID namely Bocce. In this sport, underhand roll in constantly trained. Thus, to improve the other skills, the same method can be applied; conducting sports competition especially designed for children with ID involving those skills.

TABLE II. CORRELATION BETWEEN BMI, LOCOMOTOR SKILLS, OBJECT CONTROL SKILLS, AND GROSS MOTOR SKILLS

\begin{tabular}{|c|c|c|c|}
\hline & Body Mass Index & Locomotor & Object Control \\
\hline \multirow{2}{*}{ Locomotor } & $-0,366^{*}$ & & \\
\hline & $P=0,047$ & & \\
\hline \multirow{2}{*}{ Object Control } & $-0,506^{*}$ & 0,301 & \\
\hline & $P=0,004$ & $P=0,105$ & \\
\hline \multirow[t]{2}{*}{ Gross Motor Skills } & $-0,528^{* *}$ & $0,939^{* *}$ & $0,602^{* *}$ \\
\hline & $P=0,003$ & $P=0,000$ & $P=0,000$ \\
\hline
\end{tabular}

**. Correlation is significant at the 0.01 level (2-tailed).

Table 2 shows the correlation among BMI, locomotor skills, object control skills, and gross motor skills. From the table, it can be seen that the coefficient correlation between GMS and BMI is -0.565 meaning that there is a strong negative correlation between both variables. Furthermore, the value of $\mathrm{P}$ $=0.001$ strengthens that there is a significant relationship between the two variables. In addition, the other correlation shown in table two is between locomotor skills and BMI $(0.482)$ with the value of coefficient correlation -0.456 . This indicates that there is a moderate negative correlation between locomotors and BMI and also between object control and BMI. Whereas, each of $\mathrm{P}$ values 0.007 and 0.011 explains that there is a significant relationship between the variables.

Figure 3 shows that the mean of GMS based on BMI category is comprised of three covering normal, overweight, and obese. In this case, the mean of normal category $=58.20$ and $\mathrm{SD}=8.91$; the mean of overweight category $=55.00$ and $\mathrm{SD}=7.04 ;$ and the mean of obese category $=45.75$ and $\mathrm{SD}=$ 4.16 .

The data analyzed in this study has proven that there is a significant negative correlation between GMS and BMI $(r=-$ $0,565 ; \mathrm{P}=0,001)$. Thus, it is safe to say that the higher the score of BMI gets, the lower the score of GMS is. This fact means that the lack of gross motor skills is caused by BMI or the obesity level of children with ID is caused by the lack of gross motor skills. Logically, the lack of gross motor skills can cause reluctance in participating in sport so that they do not release much energy which leads to obesity [25].

\section{CONCLUSION}

The results of the study show that the less gross motor skills the children have, the bigger their chance to get obese. This indicates that children with better gross motor skills are more likely to be healthier at least in terms of BMI. One of the implications of the results of the study is that if the gross motor skills of children with ID are constantly trained, they will have more chances to either perform better or have ideal body 
weight. Therefore, it is recommended that future researchers focus more on how to improve their gross motor skills.

The other implication this study finds is that the correlation value of GMS and BMI of children with ID is lower than the values of the same study in other countries. This means that there is lack of attention on sport for disabled people. In some countries, especially developed ones, there is a major in universities concerning with sport for disabled people. Thus, Indonesia needs to start considering this."

\section{ACKNOWLEDGMENT}

This study funded by Universitas Pendidikan Indonesia.

\section{REFERENCES}

[1] L. Woodfield, Physical development in the early years. Bloomsbury Publishing, 2004.

[2] S. Stork and S. W. Sanders, "Physical education in early childhood," Elem. Sch. J., vol. 108, no. 3, pp. 197-206, 2008

[3] E. A. Haapala, "Cardiorespiratory Fitness and Motor Skills in Relation to Cognition and Academic Performance in Children - A Review," J. Hum. Kinet., vol. 36, no. 1, pp. 55-68, 2013.

[4] S. J. Downs, S. J. Fairclough, Z. R. Knowles, and L. M. Boddy, "Physical activity patterns in youth with intellectual disabilities," Adapt. Phys. Act. Q., vol. 33, no. 4, pp. 374-390, 2016.

[5] P. Rintala and E. M. Loovis, "Measuring Motor Skills in Finnish Children With Intellectual Disabilities.," Percept. Mot. Ski., vol. 116, no. 1, pp. 294-303, 2013.

[6] J. Simons, D. Daly, F. Theodorou, C. Caron, J. Simons, and E. Andoniadou, "Validity and Reliability of the TGMD-2 in 7-10 Year Old Flemish Children With Intellectual Disability,” Adapt. Phys. Act. Q., pp. 71-82, 2007.

[7] N. C. Valentini, "Validity and reliability of the TGMD-2 for Brazilian children," J. Mot. Behav., vol. 44, no. 4, pp. 275-280, 2012.

[8] B. C. Spessato, C. Gabbard, L. Robinson, and N. C. Valentini, "Body mass index, perceived and actual physical competence: The relationship among young children," Child. Care. Health Dev., vol. 39, no. 6, pp. 845-850, 2013

[9] S.-C. Yang, S.-J. Lin, and C.-Y. Tsai, "Effect of Sex, Age, and BMI on the Development of Locomotor Skills and Object Control Skills among Preschool Children," Percept. Mot. Skills, vol. 121, no. 3, pp. 873-888, 2015.

[10] A. De Meester, "Associations among Elementary School Children's Actual Motor Competence, Perceived Motor Competence, Physical Activity and BMI: A Cross-Sectional Study,” PLoS One, vol. 11, no. 10, p. e0164600, Oct. 2016
[11] S. Bhaumik, J. M. Watson, C. F. Thorp, F. Tyrer, and C. W. McGrother, "Body mass index in adults with intellectual disability: distribution, associations and service implications: a population-based prevalence study," J. Intellect. Disabil. Res., vol. 52, no. 4, pp. 287-298, 2008

[12] E. Emerson, C. Hatton, S. Baines, and J. Robertson, "The physical health of British adults with intellectual disability: cross sectional study,” Int. J. Equity Health, vol. 15, no. 1, p. 11, 2016.

[13] J. E. Shaw, Baker I. H., D. I. Sicree, and P. Zimmet, "Global estimates of the prevalence of diabetes for 2010 and 2030," Diabetes Res. Clin. Pract., vol. 87, no. 1, pp. 4-14, 2010

[14] G. C. Frey and B. Chow, "Relationship between BMI, physical fitness, and motor skills in youth with mild intellectual disabilities," Int. J. Obes., vol. 30, no. 5, pp. 861-867, 2006

[15] D. Wechsler, Manual for the Wechsler intelligence scale for children, revised. Psychological Corporation, 1974.

[16] D. Ulrich, The test of gross motor development. Austin: TX: Prod-Ed., 2000.

[17] S. Houwen, E. Hartman, L. Jonker, and C. Visscher, "Reliability and validity of the TGMD-2 in primary-school-age children with visual impairments," Adapt. Phys. Act. Q., vol. 27, no. 2, pp. 143-159, 2010.

[18] S. Kim, M. J. Kim, N. C. Valentini, and J. E. Clark, "Validity and reliability of the TGMD-2 for South Korean children.," J. Mot. Behav., vol. 46, no. 5, 2014.

[19] M. A. Soltanian, A. Farokhi, R. Ghorbani, A. A. Jaberi Moghaddam, and M. Zarezade, "Evaluation of the reliability and construct validity of test of gross motor development-2 (Ulrich 2) in children of Semnan province," Koomesh, vol. 14, no. 2. Semnan University of Medical Sciences (Bolvar Basij, Semnan 35195-163, Iran, Islamic Republic of), pp. 200-206, 2012.

[20] K. Y. A. Wong and S. Yin Cheung, "Confirmatory factor analysis of the test of gross motor development-2," Meas. Phys. Educ. Exerc. Sci., vol. 14, no. 3, pp. 202-209, 2010.

[21] Y. Kim, I. Park, and M. Kang, "Examining rater effects of the TGMD-2 on children with intellectual disability," Adapt. Phys. Act. Q., vol. 29, no. 4, pp. 346-365, 2012.

[22] T. J. Cole, M. C. Bellizzi, K. M. Flegal, and W. H. Dietz, "Establishing a standard definition for child overweight and obesity worldwide: international survey.," BMJ, vol. 320, no. 7244, pp. 1240-3, 2000.

[23] Cohen J., Statistical Power Analysis for the Behavioral Sciences. Hillsdale, NJ,: Lawrence Erlbaum Associations, 1988.

[24] C.-C. Pan, R. Davis, D. Nichols, S. H. Hwang, and K. Hsieh, "Prevalence of overweight and obesity among students with intellectual disabilities in Taiwan: A secondary analysis," Res. Dev. Disabil., vol. 53, pp. 305-313, 2016.

[25] M. Westendorp, E. Hartman, S. Houwen, J. Smith, and C. Visscher, "The relationship between gross motor skills and academic achievement in children with learning disabilities," Res. Dev. Disabil., vol. 32, no. 6, pp. 2773-2779, 2011

[26] K. Sultoni, A. Suherman, and R. Wibowo, "Increasing Gross Moto Skill Through Fundamental Skill Development Program,” J. Phys. Educ., vol. 7, no. 1, pp. 39-43, 2018 